Review

\title{
Aberrant Lipid Metabolism: An Emerging Diagnostic and Therapeutic Target in Ovarian Cancer
}

\author{
Carmen E. Pyragius ${ }^{1}$, Maria Fuller ${ }^{2}$, Carmela Ricciardelli ${ }^{1}$ and Martin K. Oehler ${ }^{1,3, *}$ \\ 1 Discipline of Obstetrics and Gynaecology, School of Paediatrics and Reproductive Health, \\ Research Centre for Reproductive Health, Robinson Institute, University of Adelaide, \\ Adelaide 5005, Australia; E-Mails: carmen.macsai@adelaide.edu.au (C.E.P.); \\ carmela.ricciardelli@adelaide.edu.au (C.R.) \\ 2 Genetics and Molecular Pathology, SA Pathology, Women's and Children's Hospital, \\ Adelaide 5006, Australia; E-Mail: maria.fuller@adelaide.edu.au \\ 3 Department of Gynaecological Oncology, Royal Adelaide Hospital, Adelaide 5000, Australia \\ * Author to whom correspondence should be addressed; E-Mail: martin.oehler@adelaide.edu.au; \\ Tel.: +61-8-8222-4816; Fax: +61-8-8222-5952.
}

Received: 1 February 2013; in revised form: 6 March 2013 / Accepted: 7 March 2013 /

Published: 10 April 2013

\begin{abstract}
Ovarian cancer remains the most lethal gynaecological cancer. A better understanding of the molecular pathogenesis of ovarian cancer is of critical importance to develop early detection tests and identify new therapeutic targets that would increase survival. Cancer cells depend on de novo lipid synthesis for the generation of fatty acids to meet the energy requirements for increased tumour growth. There is increasing evidence that lipid metabolism is deregulated in cancers, including ovarian cancer. The increased expression and activity of lipogenic enzymes is largely responsible for increased lipid synthesis, which is regulated by metabolic and oncogenic signalling pathways. This article reviews the latest knowledge on lipid metabolism and the alterations in the expression of lipogenic enzymes and downstream signalling pathways in ovarian cancer. Current developments for exploiting lipids as biomarkers for the detection of early stage ovarian cancer and therapeutic targets are discussed. Current research targeting lipogenic enzymes and lipids to increase the cytotoxicity of chemotherapy drugs is also highlighted.
\end{abstract}

Keywords: ovarian cancer; lipid synthesis; signalling pathways; biomarkers; therapeutic targets 


\section{Introduction}

Ovarian cancer is the most lethal gynaecological cancer and ranks as the fourth most common cause of cancer-related death in women in the Western world [1]. The poor prognosis is largely attributed to a lack of early detection and, consequently, approximately $70 \%$ of patients present with advanced-stage metastatic disease. The treatment for advanced ovarian cancer is debulking surgery followed by platinum- and taxane-based chemotherapy. This standard treatment results in a complete response rate of $40 \%-60 \%$; however, more than $90 \%$ of patients relapse after 18 months and, with the emergence of chemoresistance, ultimately die from the disease [2]. Significant improvements in ovarian cancer survival will require the development of more effective molecularly targeted diagnostics and/or therapeutics.

In recent years, the field of cancer cell metabolism has been progressing rapidly. Cancer cells rely on de novo lipid synthesis for the generation of fatty acids to meet the needs of tumour growth, resulting in specific alterations in different aspects of lipid metabolism. These alterations can influence the availability of structural lipids for the synthesis of membranes, the production and degradation of lipids for energy supply and the abundance of lipids with signalling functions. Altered lipid metabolism is detected in ovarian cancer patients during early and late stages of disease, including patients with recurrent disease, when compared to healthy controls $[3,4]$. Consequently, there is convincing evidence to support a pivotal role of increased lipid synthesis in the development of ovarian cancer. The main classes of lipids implicated in the pathogenesis of ovarian cancer include the phospholipids and sphingolipids. Multiple pathways are involved in the synthesis and degradation of these lipid groups, involving changes in the expression and activity of enzymes regulating their metabolism.

This article reviews the latest knowledge on lipid metabolism in ovarian cancer cells and the alterations in the expression of lipogenic enzymes and signalling pathways. Current developments in the application of lipids as biomarkers in the detection of early stage ovarian cancer are discussed. Furthermore, research employed to overcome chemotherapy resistance by targeting lipogenic enzymes and lipids to increase the cytotoxicity of chemotherapy drugs is also highlighted.

\section{Lipid Metabolism in Ovarian Cancer}

Abnormal lipid metabolism, leading to increased lipid synthesis, is found to play an important role in the pathogenesis of malignancies, including ovarian cancer [5]. Cancer cells depend on de novo lipid synthesis for the generation of fatty acids to meet the needs of tumour growth [6]. The increased expression and activity of lipogenic enzymes is largely responsible for increased synthesis of long-chain fatty acids in cancer cells $[7,8]$. Changes in the expression and activity of enzymes involved in lipid metabolism are regulated by metabolic and oncogenic signalling pathways $[9,10]$. Common enzymes identified in a variety of human malignancies include ATP citrate lyase (ACL), acetyl-CoA carboxylase (ACC) and fatty acid synthase (FAS) [7,11,12]. These enzymes are essential in the biosynthesis of fatty acids, converting cytosolic citrate to acetyl-CoA (the precursor for fatty acids and cholesterol), followed by the production of malonyl-CoA, which is further converted to produce fatty acids, respectively. The expression and activity of ACL, ACC and FAS are regulated by complex interactions between numerous signalling pathways. For example, the phosphatidylinositol 3-kinase-Akt (PI3K-Akt) and LKB1/AMPK signalling pathways can increase enzyme activity via 
direct phosphorylation or by sterol regulatory element-binding protein (SERBP)-mediated transcription of lipogenic genes $[9,10,13]$. Other signalling components, including oncoproteins and tumour suppressors, regulate fatty acid synthesis, leading to alterations in the production of fatty acid precursors generated from both glucose and glutamine metabolism. In particular, tumour suppressor p53 regulates fatty acid synthesis via the pentose phosphate pathway (PPP) and suppresses glucose consumption, NADPH production and biosynthesis [14]. The PPP is also regulated by a target protein of p53, TIGAR, which decreases levels of fructose-6-phosphate, resulting in an inhibition of glycolysis and fatty acid synthesis [15]. p53 can also increase fatty acid synthesis via the enhanced expression of glutaminase 2 [16]. The increased synthesis of long-chain fatty acids provides cancer cells with the structural building blocks, signalling molecules, post-translational modification of proteins and energy required for membrane synthesis, cell survival, proliferation, migration and invasion, which are important for the initiation and progression of tumours [17].

Normal cells acquire fatty acids to meet their metabolic demands from exogenous sources, including dietary lipids. A high intake of dietary lipids, including food with a high level of saturated fat or cholesterol, such as red meat, eggs and dairy products, is a well a known risk factor for ovarian cancer [18-20]. A higher consumption of fats and cholesterol can increase the risk of ovarian cancer through increased levels of circulating estrogen and/or progesterone [21]. The exposure of the ovarian epithelium to these hormones during ovulation may contribute to malignant transformation and tumour development $[21,22]$. Nonetheless, the increased rate of de novo lipid synthesis that occurs during oncogenesis to meet the needs of tumour growth is shown to be irrespective of the nutritional load [23]. Interestingly, adipocyte derived lipids were shown to act as an energy source for ovarian cancer cells, and co-culture with adipocytes resulted in the transfer of lipids to ovarian cancer cells, promoting tumour growth in vitro and in vivo [24].

\section{Fatty Acid Synthase (FAS)}

The increased expression of fatty acid synthase (FAS) is associated with a poor prognosis in a variety of human malignancies, including ovarian cancer [7,25]. The correlation between elevated FAS and enhanced tumour growth is attributed to the role of FAS activity in phospholipid synthesis. FAS activity is shown to drive phospholipid synthesis in the endoplasmic reticulum (ER), promoting ER homeostasis and, consequently, cell survival [26]. Treatment of a variety of cell lines with FAS inhibitors induces ER stress in tumour cells, inducing cell death [27] and inhibiting fatty acid synthesis [28]. Treatment of SKOV3 human ovarian cancer cells with a synthetic FAS inhibitor (C93) led to the activation of AMP-activated protein kinase (AMPK) and cell death [29]. Treatment of SKOV3 xenograft bearing mice with C93 also had a significant anti-tumour effect, causing a reduction in both tumour growth and volume [29]. The FAS inhibitor C75 has recently been shown to significantly reduce cell proliferation and induce apoptosis in ovarian clear cell carcinoma cell lines [30] and was attributed to the downregulation of the oncogenic phosphoinositide-3-kinase (PI3K) signalling pathway [31]. 


\section{Lipids}

\subsection{Phospholipids}

Phospholipids are commonly associated with cancer and have been identified in almost every type of malignancy [32]. Phospholipids are a major component of all cell membranes, spontaneously forming lipid bilayers. Lysophosphatidic acid (LPA) is a lysophospholipid that functions as an extracellular signalling molecule and mediates a variety of biological processes by binding to a family of cell surface $G$ protein-coupled receptors [33]. These include LPA receptors belonging to the endothelial differentiation gene (Edg) family $\left(\mathrm{LPA}_{1} / \mathrm{Edg} 2, \mathrm{LPA}_{2} / \mathrm{Edg} 4, \mathrm{LPA}_{3} / \mathrm{Edg} 7\right)$ [33], the purinergic family (GPR23/P2Y9/LPA $)$ [34] and the related receptors, GPR92/LPA 5 [35] and P2Y5/LPA 6 [36]. Receptors from the purinergic family and related receptors are structurally different to those from the well-characterised $\mathrm{LPA}_{1-3}$ receptors [34,37]. LPA receptors, in particular $\mathrm{LPA}_{2}$, are shown to play a significant role in the pathogenesis of a variety of human malignancies, including epithelial ovarian cancer (EOC) [38,39].

LPA is secreted by several cell types, detected in many biological fluids, and stimulates cancer cell proliferation, migration and survival [40]. High levels of LPA are produced by ovarian cancer cells [40-42]. LPA is also elevated in the ascites of ovarian cancer patients $[42,43]$. It was recently demonstrated that LPA in EOC ascites is an important mediator of tumour-promoting effects in conjunction with phospholipase A2 (PLA 2 ) activity (discussed below) [44].

Several studies have demonstrated that LPA activates proteolytic enzymes, including urokinase plasminogen activator (uPA) [45-47], matrix metalloproteinases (MMPs) MMP-2 [48] and MMP-9 [49] and VEGF [50-52], to augment ovarian cancer invasion and metastasis. The Ras/Rho/ROCK pathways are shown to contribute to LPA-induced proteolytic enzyme production $[49,53,54]$. LPA is shown to activate the Ras/Rho/ROCK pathways, to stimulate NF-kB, inducing the expression of MMP-9 and uPA, leading to the degradation of the basement membrane and various components of the extracellular matrix, respectively [49,55]. Furthermore, the $\mathrm{LPA}_{2}$ receptor was shown to be important in LPA-induction of uPA in ovarian cancer cells [46]. Inhibition of $\mathrm{LPA}_{2}$ receptor decreased LPA-induced uPA by over $50 \%$ and led to a reduction in invasion and migration of ovarian cancer cells [46]. Proteolytic enzyme production was also shown to be cell line-specific, where LPA induced the expression of uPA in SKOV-3 cells, but not MMP-9, whilst LPA induced the expression of MMP-9 in CAOV-3 cells [45,49]. Increased expression of VEGF results in increased angiogenesis and, therefore, increased tumour growth [50]. LPA stimulated the transcriptional activity of VEGF through c-Myc and Sp-1 independent of HIF-1 $\alpha$ [52]. The Rho-ROCK pathway, which lies upstream of c-Myc, was also shown to contribute to LPA-induced VEGF expression [52].

LPA is also a major regulator of the chemokine growth-regulated oncogene $\alpha$ (GRO $\alpha)$. GRO $\alpha$ expression is identified in a number of human cancers and is associated with tumorigenesis, angiogenesis and metastasis [56-58]. More recently, elevated levels of GRO $\alpha$ were found in plasma and ascites in a high percentage of ovarian cancer patients [59]. In ovarian cancer cell lines, GRO $\alpha$ expression was not constitutive; however, strongly stimulated by LPA and mediated primarily by $\mathrm{LPA}_{2}$ receptors though the transcriptional activation of the GRO $\alpha$ promoter [59]. A recent study demonstrated that LPA regulates the sterol regulatory element binding protein-FAS (SREBP-FAS) and 
AMP-activated protein kinase-ACC pathways (AMPK-ACC) resulting in increased de novo lipid synthesis in ovarian cancer cells [38]. In addition, LPA-induced lipid synthesis was mediated via $\mathrm{LPA}_{2}$ receptors [38], further supporting the importance of $\mathrm{LPA}_{2}$ signalling in the pathogenesis of ovarian cancer.

\subsubsection{Autotaxin (ATX)}

Circulating LPA is primarily produced by autotoxin (ATX), a secreted enzyme, which has lysophospholipase D activity [60,61]. ATX is a member of the ectonucleotide pyrophosphatase and phosphodiesterase family of enzymes. It is a type II membrane protein synthesized as a secreted protein. ATX has lysophospholipase D activity, which enables it to convert lysophosphatidylcholine (LPC) into LPA [61]. Through its lysophospholipase D activity, ATX has been shown to act as a chemotactic factor, to stimulate angiogenesis [62] and to increase invasiveness and metastatic potential in transformed cells [63]. ATX was shown to be involved in ascites-induced migration of EOC [44]. Interestingly, although increased expression of ATX has been associated with increased cancer progression, ATX antigen levels in serum were not increased in ovarian cancer patients when compared to healthy controls [64]. Furthermore, ATX may not be useful as a diagnostic marker for ovarian cancer, as ATX is also elevated in other conditions, including liver disease, acute coronary syndrome and pregnancy [65-67].

\subsubsection{Phospholipase A}

LPA is also produced by the actions of phospholipase A, PLA 1 and $\mathrm{PLA}_{2}$ [68]. High levels of cytosolic and calcium-independent $\mathrm{PLA}_{2}$ activity were found in human EOC ascites, concurrent with elevated levels of LPC, arachidonic acid, LPA and lipid products of PLA 2 [44]. Furthermore, a high level of $\mathrm{PLA}_{2}$ activity was observed in EOC tissues when compared to either benign or normal tissues [44]. $\mathrm{PLA}_{2}$ in ascites was also shown to induce the proliferation, invasion and migration of human EOC [44].

\subsubsection{Phospholipase D (PLD)}

Phospholipase D (PLD) is an enzyme that converts membrane phospholipids to phosphatidic acid (PA), a precursor of LPA. PLD activity is increased in ovarian cancer cells by the integrin receptor signalling pathway [69]. PLD is implicated in cell spreading of ovarian cancer cells after PA was found to interact directly with Racl and to mediate the translocation of GTP-Rac1 to the plasma membrane [69]. This activated downstream p21-activated kinase, inducing integrin-mediated lamellipodia formation and cell spreading. A number of ovarian cancer cell lines constitutively express LPA [70]. In SKOV3 ovarian cancer cells that constitutively produced LPA, inhibition of PLD activity resulted in a 50\% reduction of LPA levels [70]. Interestingly, OVCAR-3 ovarian cancer cells were shown to increase LPA production following treatment with LPA at a concentration similar to that found in patient ascites. This was reduced by $60 \%$ following the addition of an inhibitor of PLD activity [70]. These findings indicate that activity of PLD is associated with both constitutive and LPA-induced LPA production in ovarian cancer cells [70]. 


\subsection{Sphingolipids}

Altered sphingolipid metabolism is also associated with the pathogenesis of a variety of human malignancies and includes changes in the levels of sphingolipids and the enzymes involved in their metabolism [71]. Ceramides, short chain sphingolipids, have been most extensively studied in cancer, due to their involvement in apoptosis. Ceramides are bioactive lipids and are primarily formed by the hydrolysis of sphingomyelin, following activation of acid or neutral sphingomyelinase or by de novo synthesis involving $\mathrm{N}$-acylation of dihydrosphingosine [72]. They are proapoptotic metabolites and known tumour-suppressors. The administration of ceramide analogues can inhibit tumour growth in a variety of cancer cell lines, both in vitro and in vivo [73-76]. Regulated by many enzymes, ceramides give rise to more complex sphingolipids, including sphingosine 1-phosphate (S1P), a bioactive lipid shown to promote cell survival. S1P is formed following activation of the enzyme sphingosine kinase (SphK). The isoform SphK1 is activated in human ovarian cancer cells, leading to resistance to the chemotherapy drug, 4-HRP [77]. The ability of S1P to facilitate the survival of cancer cells is in direct contrast to the proapoptotic activity of ceramide, and consequently, it is suggested that the ratio of these two lipids are important in cancer development [78,79].

\subsection{Glycosphingolipids}

Ceramides can also lead to the synthesis of glycosphingolipids, including sulphatides and gangliosides. Sulphatides (ST), membrane-sulphated glycolipids, have been reported to be elevated in ovarian cancer [80,81]. Microarray analysis revealed an increase in the mRNA expression of enzymes involved in ST synthesis in microdissected epithelial ovarian cancer cells, when compared to normal tissue [80]. However, their role in the pathogenesis of ovarian cancer remains to be elucidated.

\section{Lipids as Diagnostic Markers and Therapeutic Targets in Ovarian Cancer}

\subsection{Diagnostic Markers}

Lipid biomarker discovery is of particular interest in ovarian cancer, as mortality could be reduced significantly by an early detection test. However, only a few studies have been reported to date investigating lipids as diagnostic ovarian cancer markers. Some promising lipid biomarkers are shown in Table 1. Studies investigating the potential role for LPA as an early detection marker presented conflicting results. LPA levels were shown to be significantly elevated in ovarian cancer patients when compared to controls in some studies [4,41]; however, other researchers found no differences [43] or even contrary results [4]. These differing results can potentially be attributed to differing methodology and/or sample type. An ongoing clinical trial is currently validating the utility of a new assay for LPA for the early detection of ovarian cancer [82].

Analysis of EOC tissue using liquid chromatography electrospray ionization-tandem mass spectrometry (LC-ESI-MS/MS) revealed elevated levels of sulphatides (ST) when compared to normal ovarian tissue [80]. Matrix-assisted laser desorption ionization-tissue-imaging MS detected, as well as localized, ST in areas of epithelial ovarian carcinoma, further supporting the potential of ST as a biomarker in ovarian cancer. Using fluorometric assays, $\mathrm{PLA}_{2}$ was identified as a potential diagnostic 
maker after increased activity levels were observed in human EOC tissues when compared to either benign or normal tissues [44].

Table 1. Altered lipid metabolism in ovarian cancer: potential diagnostic markers.

\begin{tabular}{|c|c|c|}
\hline Marker & Studies/Methods & References \\
\hline LPA & LPA assays under development in clinical trials. & [82] \\
\hline Sulphatides & $\begin{array}{l}\text { Elevation of sulphatides in EOC tissue compared to normal tissue by mass } \\
\text { spectrometry (LC ESI-MS/MS). }\end{array}$ & {$[80]$} \\
\hline $\mathrm{PLA}_{2}$ & $\begin{array}{l}\text { Elevated activity of } \mathrm{PLA}_{2} \text { in EOC tissue, compared to benign tumours and } \\
\text { normal tissue using fluorometric assays. }\end{array}$ & {$[44]$} \\
\hline \multirow{2}{*}{ LPLs } & $\begin{array}{l}\text { Increased levels of LPA, LPI and SIP in plasma from ovarian cancer } \\
\text { patients compared to healthy controls using ESI-MS. }\end{array}$ & {$[3,41]$} \\
\hline & $\begin{array}{l}\text { Predictive markers with a significant difference between levels of SIP, LPA } \\
\text { and LPC between preoperative and postoperative ovarian cancer patients. }\end{array}$ & {$[41]$} \\
\hline LPLs + CA 125 & $\begin{array}{l}\text { Serum measurements of LPLs in conjunction with CA125 greatly improved } \\
\text { diagnostic accuracy in early stage serous ovarian cancer and mucinous } \\
\text { subtypes using LC ESI-MS/MS. }\end{array}$ & {$[83]$} \\
\hline $\begin{array}{l}\text { Abbreviations: } \\
\text { lysophosphatidy }\end{array}$ & $\begin{array}{l}\text { PLA }_{2} \text {, phospholipase } A_{2} ; \text { LPLs, lysophospholipids; LPA, lysophosphati } \\
\text { inositol; LPC, Lysophosphatidylcholine; SIP, sphingosine-1-phosphate; LC ES }\end{array}$ & $\begin{array}{l}\text { acid; LPI, } \\
\text { MS, liquid }\end{array}$ \\
\hline
\end{tabular}

Lysophospholipids (LPLs) might also have potential as diagnostic and/or predictive ovarian cancer markers $[3,41,83]$. Elevated levels of LPA and lysophosphatidylinositol (LPI) were found in plasma of ovarian cancer patients using electrospray ionization-tandem mass spectrometry (ESI-MS) [3]. ESI-MS also identified a significant difference in plasma levels of LPA, LPI and sphingosine-1-phosphate (SIP) when comparing patient and control samples [41]. The potential value of LPLs as predictive markers arose after significant differences between levels of SIP, LPA and lysophosphatidylcholine (LPC) were identified between preoperative and postoperative serum samples [41]. The measurement of bioactive phospholipids, LPA, LPI, LPC and SIP, in conjunction with serum CA125 using LC ESI-MS/MS improved the accuracy of diagnosing early stage serous ovarian cancers from $65 \%$ to $82 \%$ and mucinous cancers from $44 \%$ to $88 \%$ [83].

\subsection{Therapeutic Targets}

Lipogenic enzymes and lipids are increasingly seen as potential targets of novel anti-ovarian cancer therapies. Potential components of aberrant metabolic lipid pathways, which might serve as targets to inhibit cancer growth and/or to overcome chemotherapy resistance, are listed in Table 2.

Statins are inhibitors of cholesterol synthesis, but also of the production of molecules, such as isoprenoids. These are lipid anchors for a range of signalling proteins, such as the small GTPases, Ras and Rho [84]. The statin lovastatin has recently been reported to induce apoptosis of ovarian cancer cells in a p53-independent manner and to synergize with doxorubicin, a chemotherapeutic agent used to treat recurrent ovarian cancer. Lovastatin drives ovarian tumour cell death by two mechanisms: first, by blocking HMG-CoA reductase activity, and second, by sensitizing multi-drug resistant cells to doxorubicin by a novel mevalonate-independent mechanism [85]. The efficacy of statins in 
anti-ovarian cancer therapy is currently examined in a phase II clinical study of interaction of lovastatin and paclitaxel for patients with refractory or relapsed ovarian cancer [86].

To overcome chemotherapy resistance, the effects of co-administration of ceramide with chemotherapy agents has been investigated. In human ovarian cancer cells, the co-administration of ceramide with the chemotherapy drug paclitaxel sensitized the cancer cells and doubled cell death when compared to treatment of ovarian cancer cells with paclitaxel alone [87]. In addition, following paclitaxel treatment, the expression of ceramide transport protein (CERT) was increased in chemotherapy resistant cell lines and in tumour samples of ovarian cancer patients [88]. CERT transports ceramide generated by de novo synthesis from the ER to the Golgi apparatus, where it is converted to sphingomyelin [89]. Knockdown of CERT resulted in an accumulation of ceramide in the ER, increasing ER stress and sensitivity of cancer cells to paclitaxel treatment [88]. Consequently, ceramide has also become a therapeutic target in ovarian cancer.

Table 2. Altered lipid metabolism in ovarian cancer: potential therapeutic targets.

\begin{tabular}{cclll}
\hline Target & Treatment & \multicolumn{1}{c}{ Effect } & References \\
\hline Cholesterol & Statins & Induce apoptosis of ovarian cancer cells. In clinical trials. & [85,86] \\
\hline \multirow{2}{*}{ FAS } & C93 & $\begin{array}{l}\text { Increases cytotoxicity of carboplatin and paclitaxel. Induces } \\
\text { in vitro and reduces tumour growth in xenograft mouse model. }\end{array}$ & death \\
\cline { 2 - 5 } & C75 & $\begin{array}{l}\text { Reduces cell proliferation in ovarian clear cell carcinoma cell lines. Inhibits } \\
\text { growth and survival of ovarian cancer cells in vitro. }\end{array}$ & [30,31] \\
\hline ATX & ccPA & Increases cytotoxicity of carboplatin. & [90] \\
\hline ENPP2 & siRNA & Increases apoptosis of cancer cells with carboplatin. & [90] \\
\hline Ceramide & Ceramide & $\begin{array}{l}\text { Co-administration with the chemotherapy drugs, paclitaxel or carboplatin, } \\
\text { sensitises cancer cells, increasing cell death. }\end{array}$ & [87] \\
\hline CERT & siRNA & Sensitises cancer cells to paclitaxel. & [88] \\
\hline
\end{tabular}

Abbreviations: Fas, fatty acid synthase; ATX, autotaxin; ccPA, 2-carbacyclic phosphatidic acid; ENPP2, ectonucleotide pyrophosphatase/phosphodiesterase 2; CERT, ceramide transport protein.

The FAS inhibitor, C93, has been shown to greatly increase the cytotoxicity of the chemotherapy drugs carboplatin and paclitaxel in ovarian cancer cells [25], thereby highlighting the potential of this inhibitor as a drug to overcome chemotherapy resistance and disease recurrence. A more recently identified inhibitor of FAS, P75, significantly reduced cell proliferation in ovarian clear cell carcinoma [30] and decreased cell proliferation and induced apoptosis in ovarian cancer cells [31].

The gene ectonucleotide, pyrophosphatase/phosphodiesterase 2 (ENPP2), which encodes ATX, was identified as a potential gene causing platinum-resistance in ovarian cancer [90]. Inhibition of ENPP2 and ATX using siRNA and 2-carbacyclic phosphatidic acid, respectively, led to increased carboplatin-induced apoptosis of ovarian cancer cells. In addition, expression of ATX in the ovarian cancer cell line, OVCAR-3, delayed apoptosis, suggesting that ATX inhibits cell death induced by the chemotherapy drug carboplatin [90]. 


\section{Conclusions}

Abnormal lipid metabolism plays an important role in the pathogenesis of ovarian cancer. The activity of lipid metabolizing enzymes is regulated by a complex interplay between metabolic and oncogenic signalling pathways. Components of the aberrant lipid metabolism pathways are promising targets for the development of novel ovarian cancer diagnostics and therapeutics. Several diagnostic markers with potential for the early detection of ovarian cancer have been identified. LPA and LPLs show the most promise, with elevated plasma levels identified in ovarian cancer patients. Therapeutic targets that have shown the greatest potential include statins, as well as ceramides. Both statins and ceramides are successful in inducing ovarian cancer cell death, as well as sensitising cancer cells to chemotherapeutic drugs. FAS inhibitors, C93 and C75, which inhibit the growth and survival of ovarian cancer cells, also show promise. LPA and statins are currently under investigation in clinical trials for their potential in the detection and treatment of ovarian cancer, respectively. This review highlights the important role of abnormal lipid metabolism in the development and progression of ovarian cancer.

\section{Acknowledgements}

This work was supported by the Ovarian Cancer Research Foundation (OCRF), Australia.

\section{Conflict of Interest}

The authors declare no conflict of interest.

\section{References}

1. Siegel, R.; Naishadham, D.; Jemal, A. Cancer statistics, 2013. CA Cancer J. Clin. 2013, 63, 11-30.

2. Agarwal, R.; Kaye, S.B. Ovarian cancer: Strategies for overcoming resistance to chemotherapy. Nat. Rev. Cancer 2003, 3, 502-516.

3. Xiao, Y.; Chen, Y.; Kennedy, A.W.; Belinson, J.; Xu, Y. Evaluation of plasma lysophospholipids for diagnostic significance using electrospray ionization mass spectrometry (ESI-MS) analyses. Ann. N. Y. Acad. Sci. 2000, 905, 242-259.

4. Xu, Y.; Shen, Z.; Wiper, D.W.; Wu, M.; Morton, R.E.; Elson, P.; Kennedy, A.W.; Belinson, J.; Markman, M.; Casey, G. Lysophosphatidic acid as a potential biomarker for ovarian and other gynecologic cancers. JAMA 1998, 280, 719-723.

5. Tania, M.; Khan, M.A.; Song, Y. Association of lipid metabolism with ovarian cancer. Curr. Oncol. 2010, 17, 6-11.

6. Swinnen, J.V.; Esquenet, M.; Goossens, K.; Heyns, W.; Verhoeven, G. Androgens stimulate fatty acid synthase in the human prostate cancer cell line lncap. Cancer Res. 1997, 57, 1086-1090.

7. Gansler, T.S.; Hardman, W., 3rd; Hunt, D.A.; Schaffel, S.; Hennigar, R.A. Increased expression of fatty acid synthase (oa-519) in ovarian neoplasms predicts shorter survival. Hum. Pathol. 1997, $28,686-692$. 
8. Pizer, E.S.; Wood, F.D.; Heine, H.S.; Romantsev, F.E.; Pasternack, G.R.; Kuhajda, F.P. Inhibition of fatty acid synthesis delays disease progression in a xenograft model of ovarian cancer. Cancer Res. 1996, 56, 1189-1193.

9. Scaglia, N.; Chisholm, J.W.; Igal, R.A. Inhibition of stearoylcoa desaturase-1 inactivates acetyl-coa carboxylase and impairs proliferation in cancer cells: Role of ampk. PLoS One 2009, 4, doi:10.1371/journal.pone.0006812.

10. Yang, Y.A.; Han, W.F.; Morin, P.J.; Chrest, F.J.; Pizer, E.S. Activation of fatty acid synthesis during neoplastic transformation: Role of mitogen-activated protein kinase and phosphatidylinositol 3-kinase. Exp. Cell Res. 2002, 279, 80-90.

11. Chajes, V.; Cambot, M.; Moreau, K.; Lenoir, G.M.; Joulin, V. Acetyl-coa carboxylase alpha is essential to breast cancer cell survival. Cancer Res. 2006, 66, 5287-5294.

12. Migita, T.; Narita, T.; Nomura, K.; Miyagi, E.; Inazuka, F.; Matsuura, M.; Ushijima, M.; Mashima, T.; Seimiya, H.; Satoh, Y.; et al. Atp citrate lyase: Activation and therapeutic implications in non-small cell lung cancer. Cancer Res. 2008, 68, 8547-8554.

13. Li, J.N.; Mahmoud, M.A.; Han, W.F.; Ripple, M.; Pizer, E.S. Sterol regulatory element-binding protein-1 participates in the regulation of fatty acid synthase expression in colorectal neoplasia. Exp. Cell Res. 2000, 261, 159-165.

14. Jiang, P.; Du, W.; Wang, X.; Mancuso, A.; Gao, X.; Wu, M.; Yang, X. P53 regulates biosynthesis through direct inactivation of glucose-6-phosphate dehydrogenase. Nat. Cell Biol. 2011, 13, 310-316.

15. Bensaad, K.; Tsuruta, A.; Selak, M.A.; Vidal, M.N.; Nakano, K.; Bartrons, R.; Gottlieb, E.; Vousden, K.H. Tigar, a p53-inducible regulator of glycolysis and apoptosis. Cell 2006, 126, 107-120.

16. Hu, W.; Zhang, C.; Wu, R.; Sun, Y.; Levine, A.; Feng, Z. Glutaminase 2, a novel p53 target gene regulating energy metabolism and antioxidant function. Proc. Natl. Acad. Sci. USA 2010, 107, $7455-7460$.

17. Zhang, F.; Du, G. Dysregulated lipid metabolism in cancer. World J. Biol. Chem. 2012, 3, 167-174.

18. Kushi, L.H.; Mink, P.J.; Folsom, A.R.; Anderson, K.E.; Zheng, W.; Lazovich, D.; Sellers, T.A. Prospective study of diet and ovarian cancer. Am. J. Epidemiol. 1999, 149, 21-31.

19. La Vecchia, C.; Decarli, A.; Negri, E.; Parazzini, F.; Gentile, A.; Cecchetti, G.; Fasoli, M.; Franceschi, S. Dietary factors and the risk of epithelial ovarian cancer. J. Natl. Cancer Inst. 1987, 79, 663-669.

20. Pan, S.Y.; Ugnat, A.M.; Mao, Y.; Wen, S.W.; Johnson, K.C. A case-control study of diet and the risk of ovarian cancer. Cancer Epidemiol. Biomarkers Prev. 2004, 13, 1521-1527.

21. Risch, H.A.; Jain, M.; Marrett, L.D.; Howe, G.R. Dietary fat intake and risk of epithelial ovarian cancer. J. Natl. Cancer Inst. 1994, 86, 1409-1415.

22. Risch, H.A. Hormonal etiology of epithelial ovarian cancer, with a hypothesis concerning the role of androgens and progesterone. J. Natl. Cancer Inst. 1998, 90, 1774-1786.

23. Menendez, J.A.; Lupu, R. Fatty acid synthase and the lipogenic phenotype in cancer pathogenesis. Nat. Rev. Cancer 2007, 7, 763-777.

24. Nieman, K.M.; Kenny, H.A.; Penicka, C.V.; Ladanyi, A.; Buell-Gutbrod, R.; Zillhardt, M.R.; Romero, I.L.; Carey, M.S.; Mills, G.B.; Hotamisligil, G.S.; et al. Adipocytes promote ovarian cancer metastasis and provide energy for rapid tumor growth. Nat. Med. 2011, 17, 1498-1503. 
25. Ueda, S.M.; Yap, K.L.; Davidson, B.; Tian, Y.; Murthy, V.; Wang, T.L.; Visvanathan, K.; Kuhajda, F.P.; Bristow, R.E.; Zhang, H.; et al. Expression of fatty acid synthase depends on nac1 and is associated with recurrent ovarian serous carcinomas. J. Oncol. 2010, 2010, 285191.

26. Swinnen, J.V.; van Veldhoven, P.P.; Timmermans, L.; de Schrijver, E.; Brusselmans, K.; Vanderhoydonc, F.; van de Sande, T.; Heemers, H.; Heyns, W.; Verhoeven, G. Fatty acid synthase drives the synthesis of phospholipids partitioning into detergent-resistant membrane microdomains. Biochem. Biophys. Res. Commun. 2003, 302, 898-903.

27. Little, J.L.; Wheeler, F.B.; Fels, D.R.; Koumenis, C.; Kridel, S.J. Inhibition of fatty acid synthase induces endoplasmic reticulum stress in tumor cells. Cancer Res. 2007, 67, 1262-1269.

28. Zhou, W.; Simpson, P.J.; McFadden, J.M.; Townsend, C.A.; Medghalchi, S.M.; Vadlamudi, A.; Pinn, M.L.; Ronnett, G.V.; Kuhajda, F.P. Fatty acid synthase inhibition triggers apoptosis during s phase in human cancer cells. Cancer Res. 2003, 63, 7330-7337.

29. Zhou, W.; Han, W.F.; Landree, L.E.; Thupari, J.N.; Pinn, M.L.; Bililign, T.; Kim, E.K.; Vadlamudi, A.; Medghalchi, S.M.; El Meskini, R.; et al. Fatty acid synthase inhibition activates amp-activated protein kinase in skov3 human ovarian cancer cells. Cancer Res. 2007, 67, 2964-2971.

30. Rahman, M.T.; Nakayama, K.; Rahman, M.; Katagiri, H.; Katagiri, A.; Ishibashi, T.; Ishikawa, M.; Iida, K.; Nakayama, N.; Otsuki, Y.; et al. Fatty acid synthase expression associated with nac1 is a potential therapeutic target in ovarian clear cell carcinomas. Br. J. Cancer 2012, 107, 300-307.

31. Tomek, K.; Wagner, R.; Varga, F.; Singer, C.F.; Karlic, H.; Grunt, T.W. Blockade of fatty acid synthase induces ubiquitination and degradation of phosphoinositide-3-kinase signaling proteins in ovarian cancer. Mol. Cancer Res. 2011, 9, 1767-1779.

32. Daly, P.F.; Lyon, R.C.; Faustino, P.J.; Cohen, J.S. Phospholipid metabolism in cancer cells monitored by $31 \mathrm{p}$ nmr spectroscopy. J. Biol. Chem. 1987, 262, 14875-14878.

33. Anliker, B.; Chun, J. Lysophospholipid g protein-coupled receptors. J. Biol. Chem. 2004, 279, 20555-20558.

34. Noguchi, K.; Ishii, S.; Shimizu, T. Identification of p2y9/gpr23 as a novel g protein-coupled receptor for lysophosphatidic acid, structurally distant from the edg family. J. Biol. Chem. 2003, 278, 25600-25606.

35. Lee, C.W.; Rivera, R.; Gardell, S.; Dubin, A.E.; Chun, J. Gpr92 as a new g12/13- and gq-coupled lysophosphatidic acid receptor that increases camp, lpa5. J. Biol. Chem. 2006, 281, 23589-23597.

36. Yanagida, K.; Masago, K.; Nakanishi, H.; Kihara, Y.; Hamano, F.; Tajima, Y.; Taguchi, R.; Shimizu, T.; Ishii, S. Identification and characterization of a novel lysophosphatidic acid receptor, p2y5/1pa6. J. Biol. Chem. 2009, 284, 17731-17741.

37. Choi, J.W.; Herr, D.R.; Noguchi, K.; Yung, Y.C.; Lee, C.W.; Mutoh, T.; Lin, M.E.; Teo, S.T.; Park, K.E.; Mosley, A.N.; et al. Lpa receptors: Subtypes and biological actions. Annu. Rev. Pharmacol. Toxicol. 2010, 50, 157-186.

38. Mukherjee, A.; Wu, J.; Barbour, S.; Fang, X. Lysophosphatidic acid activates lipogenic pathways and de novo lipid synthesis in ovarian cancer cells. J. Biol. Chem. 2012, 287, 24990-25000.

39. Yu, S.; Murph, M.M.; Lu, Y.; Liu, S.; Hall, H.S.; Liu, J.; Stephens, C.; Fang, X.; Mills, G.B. Lysophosphatidic acid receptors determine tumorigenicity and aggressiveness of ovarian cancer cells. J. Natl. Cancer Inst. 2008, 100, 1630-1642. 
40. Ren, J.; Xiao, Y.J.; Singh, L.S.; Zhao, X.; Zhao, Z.; Feng, L.; Rose, T.M.; Prestwich, G.D.; Xu, Y. Lysophosphatidic acid is constitutively produced by human peritoneal mesothelial cells and enhances adhesion, migration, and invasion of ovarian cancer cells. Cancer Res. 2006, 66, 3006-3014.

41. Sutphen, R.; Xu, Y.; Wilbanks, G.D.; Fiorica, J.; Grendys, E.C., Jr.; LaPolla, J.P.; Arango, H.; Hoffman, M.S.; Martino, M.; Wakeley, K.; et al. Lysophospholipids are potential biomarkers of ovarian cancer. Cancer Epidemiol. Biomarkers Prev. 2004, 13, 1185-1191.

42. Xu, Y.; Gaudette, D.C.; Boynton, J.D.; Frankel, A.; Fang, X.J.; Sharma, A.; Hurteau, J.; Casey, G.; Goodbody, A.; Mellors, A.; et al. Characterization of an ovarian cancer activating factor in ascites from ovarian cancer patients. Clin. Cancer Res. 1995, 1, 1223-1232.

43. Baker, D.L.; Morrison, P.; Miller, B.; Riely, C.A.; Tolley, B.; Westermann, A.M.; Bonfrer, J.M.; Bais, E.; Moolenaar, W.H.; Tigyi, G. Plasma lysophosphatidic acid concentration and ovarian cancer. JAMA 2002, 287, 3081-3082.

44. Cai, Q.; Zhao, Z.; Antalis, C.; Yan, L.; Del Priore, G.; Hamed, A.H.; Stehman, F.B.; Schilder, J.M.; Xu, Y. Elevated and secreted phospholipase a(2) activities as new potential therapeutic targets in human epithelial ovarian cancer. FASEB J. 2012, 26, 3306-3320.

45. Pustilnik, T.B.; Estrella, V.; Wiener, J.R.; Mao, M.; Eder, A.; Watt, M.A.; Bast, R.C., Jr.; Mills, G.B. Lysophosphatidic acid induces urokinase secretion by ovarian cancer cells. Clin. Cancer Res. 1999, 5, 3704-3710.

46. Wang, G.L.; Wen, Z.Q.; Xu, W.P.; Wang, Z.Y.; Du, X.L.; Wang, F. Inhibition of lysophosphatidic acid receptor-2 expression by RNA interference decreases lysophosphatidic acid-induced urokinase plasminogen activator activation, cell invasion, and migration in ovarian cancer skov-3 cells. Croat. Med. J. 2008, 49, 175-181.

47. Murthi, P.; Barker, G.; Nowell, C.J.; Rice, G.E.; Baker, M.S.; Kalionis, B.; Quinn, M.A. Plasminogen fragmentation and increased production of extracellular matrix-degrading proteinases are associated with serous epithelial ovarian cancer progression. Gynecol. Oncol. 2004, 92, 80-88.

48. Fishman, D.A.; Liu, Y.; Ellerbroek, S.M.; Stack, M.S. Lysophosphatidic acid promotes matrix metalloproteinase (MMP) activation and MMP-dependent invasion in ovarian cancer cells. Cancer Res. 2001, 61, 3194-3199.

49. Jeong, K.J.; Park, S.Y.; Cho, K.H.; Sohn, J.S.; Lee, J.; Kim, Y.K.; Kang, J.; Park, C.G.; Han, J.W.; Lee, H.Y. The Rho/ROCK pathway for lysophosphatidic acid-induced proteolytic enzyme expression and ovarian cancer cell invasion. Oncogene 2012, 31, 4279-4289.

50. Hu, Y.L.; Tee, M.K.; Goetzl, E.J.; Auersperg, N.; Mills, G.B.; Ferrara, N.; Jaffe, R.B. Lysophosphatidic acid induction of vascular endothelial growth factor expression in human ovarian cancer cells. J. Natl. Cancer Inst. 2001, 93, 762-768.

51. Ptaszynska, M.M.; Pendrak, M.L.; Bandle, R.W.; Stracke, M.L.; Roberts, D.D. Positive feedback between vascular endothelial growth factor-a and autotaxin in ovarian cancer cells. Mol. Cancer Res. 2008, 6, 352-363.

52. Song, Y.; Wu, J.; Oyesanya, R.A.; Lee, Z.; Mukherjee, A.; Fang, X. Sp-1 and c-myc mediate lysophosphatidic acid-induced expression of vascular endothelial growth factor in ovarian cancer cells via a hypoxia-inducible factor-1-independent mechanism. Clin. Cancer Res. 2009, 15, 492-501. 
53. Imamura, F.; Mukai, M.; Ayaki, M.; Akedo, H. Y-27632, an inhibitor of rho-associated protein kinase, suppresses tumor cell invasion via regulation of focal adhesion and focal adhesion kinase. Jpn. J. Cancer Res. 2000, 91, 811-816.

54. Sawada, K.; Morishige, K.; Tahara, M.; Ikebuchi, Y.; Kawagishi, R.; Tasaka, K.; Murata, Y. Lysophosphatidic acid induces focal adhesion assembly through rho/rho-associated kinase pathway in human ovarian cancer cells. Gynecol. Oncol. 2002, 87, 252-259.

55. Chang, H.R.; Huang, H.P.; Kao, Y.L.; Chen, S.L.; Wu, S.W.; Hung, T.W.; Lian, J.D.; Wang, C.J. The suppressive effect of rho kinase inhibitor, $\mathrm{y}-27632$, on oncogenic ras/rhoa induced invasion/migration of human bladder cancer tsgh cells. Chem. Biol. Interact. 2010, 183, $172-180$.

56. Dong, G.; Loukinova, E.; Chen, Z.; Gangi, L.; Chanturita, T.I.; Liu, E.T.; van Waes, C. Molecular profiling of transformed and metastatic murine squamous carcinoma cells by differential display and cdna microarray reveals altered expression of multiple genes related to growth, apoptosis, angiogenesis, and the nf-kappab signal pathway. Cancer Res. 2001, 61, 4797-4808.

57. Eck, M.; Schmausser, B.; Scheller, K.; Brandlein, S.; Muller-Hermelink, H.K. Pleiotropic effects of cxc chemokines in gastric carcinoma: Differences in cxcl8 and cxcl1 expression between diffuse and intestinal types of gastric carcinoma. Clin. Exp. Immunol. 2003, 134, 508-515.

58. Shintani, S.; Ishikawa, T.; Nonaka, T.; Li, C.; Nakashiro, K.; Wong, D.T.; Hamakawa, H. Growth-regulated oncogene-1 expression is associated with angiogenesis and lymph node metastasis in human oral cancer. Oncology 2004, 66, 316-322.

59. Lee, Z.; Swaby, R.F.; Liang, Y.; Yu, S.; Liu, S.; Lu, K.H.; Bast, R.C., Jr.; Mills, G.B.; Fang, X. Lysophosphatidic acid is a major regulator of growth-regulated oncogene alpha in ovarian cancer. Cancer Res. 2006, 66, 2740-2748.

60. Tokumura, A.; Majima, E.; Kariya, Y.; Tominaga, K.; Kogure, K.; Yasuda, K.; Fukuzawa, K. Identification of human plasma lysophospholipase d, a lysophosphatidic acid-producing enzyme, as autotaxin, a multifunctional phosphodiesterase. J. Biol. Chem. 2002, 277, 39436-39442.

61. Umezu-Goto, M.; Kishi, Y.; Taira, A.; Hama, K.; Dohmae, N.; Takio, K.; Yamori, T.; Mills, G.B.; Inoue, K.; Aoki, J.; et al. Autotaxin has lysophospholipase d activity leading to tumor cell growth and motility by lysophosphatidic acid production. J. Cell Biol. 2002, 158, 227-233.

62. Nam, S.W.; Clair, T.; Kim, Y.S.; McMarlin, A.; Schiffmann, E.; Liotta, L.A.; Stracke, M.L. Autotaxin (npp-2), a metastasis-enhancing motogen, is an angiogenic factor. Cancer Res. 2001, 61, 6938-6944.

63. Nam, S.W.; Clair, T.; Campo, C.K.; Lee, H.Y.; Liotta, L.A.; Stracke, M.L. Autotaxin (atx), a potent tumor motogen, augments invasive and metastatic potential of ras-transformed cells. Oncogene 2000, 19, 241-247.

64. Nakamura, K.; Igarashi, K.; Ohkawa, R.; Yokota, H.; Masuda, A.; Nakagawa, S.; Yano, T.; Ikeda, H.; Aoki, J.; Yatomi, Y. Serum autotaxin is not a useful biomarker for ovarian cancer. Lipids 2012, 47, 927-930.

65. Iwasawa, Y.; Fujii, T.; Nagamatsu, T.; Kawana, K.; Okudaira, S.; Miura, S.; Matsumoto, J.; Tomio, A.; Hyodo, H.; Yamashita, T.; et al. Expression of autotaxin, an ectoenzyme that produces lysophosphatidic acid, in human placenta. Am. J. Reprod. Immunol. 2009, 62, 90-95. 
66. Kimura, T.; Itoh, T.; Fusazaki, T.; Matsui, H.; Sugawara, S.; Ogino, Y.; Endo, H.; Kobayashi, K.; Nakamura, M. Low-density lipoprotein-cholesterol/high-density lipoprotein-cholesterol ratio predicts lipid-rich coronary plaque in patients with coronary artery disease-integrated-backscatter intravascular ultrasound study. Circ. J. 2010, 74, 1392-1398.

67. Watanabe, N.; Ikeda, H.; Nakamura, K.; Ohkawa, R.; Kume, Y.; Aoki, J.; Hama, K.; Okudaira, S.; Tanaka, M.; Tomiya, T.; et al. Both plasma lysophosphatidic acid and serum autotaxin levels are increased in chronic hepatitisc. J. Clin. Gastroenterol. 2007, 41, 616-623.

68. Aoki, J.; Inoue, A.; Okudaira, S. Two pathways for lysophosphatidic acid production. Biochim. Biophys. Acta 2008, 1781, 513-518.

69. Chae, Y.C.; Kim, J.H.; Kim, K.L.; Kim, H.W.; Lee, H.Y.; Heo, W.D.; Meyer, T.; Suh, P.G.; Ryu, S.H. Phospholipase d activity regulates integrin-mediated cell spreading and migration by inducing gtp-rac translocation to the plasma membrane. Mol. Biol. Cell. 2008, 19, 3111-3123.

70. Eder, A.M.; Sasagawa, T.; Mao, M.; Aoki, J.; Mills, G.B. Constitutive and lysophosphatidic acid (LPA)-induced LPA production: Role of phospholipase d and phospholipase a2. Clin. Cancer Res. 2000, 6, 2482-2491.

71. Ryland, L.K.; Fox, T.E.; Liu, X.; Loughran, T.P.; Kester, M. Dysregulation of sphingolipid metabolism in cancer. Cancer Biol. Ther 2011, 11, 138-149.

72. Pewzner-Jung, Y.; Ben-Dor, S.; Futerman, A.H. When do lasses (longevity assurance genes) become cers (ceramide synthases)?: Insights into the regulation of ceramide synthesis. J. Biol. Chem. 2006, 281, 25001-25005.

73. Gatt, S.; Dagan, A. Cancer and sphingolipid storage disease therapy using novel synthetic analogs of sphingolipids. Chem. Phys. Lipids 2012, 165, 462-474.

74. Radin, N.S. Killing tumours by ceramide-induced apoptosis: A critique of available drugs. Biochem. J. 2003, 371, 243-256.

75. Selzner, M.; Bielawska, A.; Morse, M.A.; Rudiger, H.A.; Sindram, D.; Hannun, Y.A.; Clavien, P.A. Induction of apoptotic cell death and prevention of tumor growth by ceramide analogues in metastatic human colon cancer. Cancer Res. 2001, 61, 1233-1240.

76. Von Haefen, C.; Wieder, T.; Gillissen, B.; Starck, L.; Graupner, V.; Dorken, B.; Daniel, P.T. Ceramide induces mitochondrial activation and apoptosis via a bax-dependent pathway in human carcinoma cells. Oncogene 2002, 21, 4009-4019.

77. Illuzzi, G.; Bernacchioni, C.; Aureli, M.; Prioni, S.; Frera, G.; Donati, C.; Valsecchi, M.; Chigorno, V.; Bruni, P.; Sonnino, S.; et al. Sphingosine kinase mediates resistance to the synthetic retinoid N-(4-hydroxyphenyl)retinamide in human ovarian cancer cells. J. Biol. Chem. 2010, 285, 18594-18602.

78. Shida, D.; Takabe, K.; Kapitonov, D.; Milstien, S.; Spiegel, S. Targeting sphk1 as a new strategy against cancer. Curr. Drug Targets 2008, 9, 662-673.

79. Spiegel, S. Sphingosine 1-phosphate: A prototype of a new class of second messengers. J. Leukoc. Biol. 1999, 65, 341-344.

80. Liu, Y.; Chen, Y.; Momin, A.; Shaner, R.; Wang, E.; Bowen, N.J.; Matyunina, L.V.; Walker, L.D.; McDonald, J.F.; Sullards, M.C.; et al. Elevation of sulfatides in ovarian cancer: An integrated transcriptomic and lipidomic analysis including tissue-imaging mass spectrometry. Mol. Cancer 2010, 9, doi:10.1186/1476-4598-9-186. 
81. Makhlouf, A.M.; Fathalla, M.M.; Zakhary, M.A.; Makarem, M.H. Sulfatides in ovarian tumors: Clinicopathological correlates. Int J. Gynecol. Cancer 2004, 14, 89-93.

82. ClinicalTrials.gov NCT00986206. Lysophosphatidic acid assay in patients with ovarian cancer or who are at risk for ovarian cancer. Available online: http://clinicaltrials.gov/show/NCT00986206 (accessed on 17 January 2013).

83. Shan, L.; Chen, Y.A.; Davis, L.; Han, G.; Zhu, W.; Molina, A.D.; Arango, H.; LaPolla, J.P.; Hoffman, M.S.; Sellers, T.; et al. Measurement of phospholipids may improve diagnostic accuracy in ovarian cancer. PLoS One 2012, 7, doi:10.1371/journal.pone.0046846.

84. Munoz-Pinedo, C.; El Mjiyad, N.; Ricci, J.E. Cancer metabolism: Current perspectives and future directions. Cell. Death Dis. 2012, 3, doi:10.1038/cddis.2011.123.

85. Martirosyan, A.; Clendening, J.W.; Goard, C.A.; Penn, L.Z. Lovastatin induces apoptosis of ovarian cancer cells and synergizes with doxorubicin: Potential therapeutic relevance. $B M C$ Cancer 2010, 10, doi:10.1186/1471-2407-10-103.

86. ClinicalTrials.gov NCT00585052. A phase II study of interaction of lovastatin and paclitaxel for patients with refractory or relapsed ovarian cancer. Available online: http://clinicaltrials.gov/ show/NCT00585052 (accessed on 16 January 2013).

87. Van Vlerken, L.E.; Duan, Z.; Seiden, M.V.; Amiji, M.M. Modulation of intracellular ceramide using polymeric nanoparticles to overcome multidrug resistance in cancer. Cancer Res. 2007, 67, 4843-4850.

88. Swanton, C.; Marani, M.; Pardo, O.; Warne, P.H.; Kelly, G.; Sahai, E.; Elustondo, F.; Chang, J.; Temple, J.; Ahmed, A.A.; et al. Regulators of mitotic arrest and ceramide metabolism are determinants of sensitivity to paclitaxel and other chemotherapeutic drugs. Cancer Cell 2007, 11, 498-512.

89. Hanada, K.; Kumagai, K.; Yasuda, S.; Miura, Y.; Kawano, M.; Fukasawa, M.; Nishijima, M. Molecular machinery for non-vesicular trafficking of ceramide. Nature 2003, 426, 803-809.

90. Vidot, S.; Witham, J.; Agarwal, R.; Greenhough, S.; Bamrah, H.S.; Tigyi, G.J.; Kaye, S.B.; Richardson, A. Autotaxin delays apoptosis induced by carboplatin in ovarian cancer cells. Cell Signal. 2010, 22, 926-935.

(C) 2013 by the authors; licensee MDPI, Basel, Switzerland. This article is an open access article distributed under the terms and conditions of the Creative Commons Attribution license (http://creativecommons.org/licenses/by/3.0/). 